\title{
The Demographic Transition and Development in Africa: The Unique Case of Ethiopia
}

\author{
edited by Charles Teller and Assefa Hailemariam \\ London-New York: Springer 2011 \\ ISBN 978-90-481-8918-2 \\ Hardcover, \$219.00, 359 pp.
}

\author{
Reviewed by Gebremariam Woldemicael \\ University of Western Ontario (London, ON) \\ gebre_wm@yahoo.com
}

In many sub-Saharan African countries-where significant improvement in economic development has not occurred; where ecological degradation, drought, civil war, political instability, and poverty have been common events for the last several years; and where demographic transition is at its early stage — a good understanding of the factors contributing to the lag of demographic change is imperative. From a strategy focused on development needs, and in light of the growing problems of ecological degradation and poverty that have ravaged the rural population of Ethiopia in the last few decades, it is essential to move to a much more comprehensive approach that goes well beyond the demographic-transition theory approach to understand the underlying factors of demographic-development relationships. Attention has to be drawn to a broader and more holistic approach, because it is often quite difficult to deal with human development issues in isolation, without consideration of the broader system within which the problem is embedded. The conceptual framework for Ethiopia presented in Figure 1.1 of this book represents the posited research approach to the population-development nexus. With the population growth rate and economic progress mismatched, and informed analyses wanting, any book with the terms demographic transition and development in the title seems timely and necessary.

The most striking feature of the book is its use of a wealth of data, taken from different censuses (e.g., 1984, 1994, 2007) and large-scale national surveys, including the 1990, 2000, and 2005 Ethiopia Demographic and Health Surveys, the 1999 and 2005 National Labour Force Surveys, the 1990 National Family \& Fertility Survey, and the 2007 Jimma Longitudinal Family Survey of Youth, as well as case studies conducted by authors. Both descriptive and advanced analyses and models, including univariate, biviariate, and multivariate models are used to examine the relationship of demographic and health outcomes with socio-economic, environmental, and geographical factors, as well as to assess the policy implications of such relationships. It is well organized and each chapter is clearly written.

The book focuses on sixteen chapters/papers, divided into seven main parts. Each of the chapters is written by one or several authors. As for the conclusion, it puts all the pieces of the conundrum together by systematically examining the sixteen chapters discussed with greater detail in previous chapters. The inclusion of such a substantial conclusion considerably increases the coherence of the book. The papers in this book, as in many edited books, are uneven. Some offer interesting approaches and/or findings to policymakers, experienced researchers, and other readers. Among those is chapter 1, a new conceptual framework of demographic response and human adaptation to societal and environmental hazards. Using a multi-level contextual approach (macro, community, and household levels), this chapter demonstrates key demographic responses (demographic dynamics, migration/labour mobility, and labour force) to a mix of poverty-related negative factors (food insecurity, environmental degradation, climate change, malnutrition, vulnerabilities, and human and natural hazards) with positive factors (improved education and health, and higher age at marriage). Another study presented here with interesting new findings is chapter 3 (Part II). Using both bivariate and multivariate analyses, the authors make a detailed and comprehensive examination of 
the nature, pace, and determinants of the incipient fertility transition in Ethiopia. Their findings reveal that although child mortality has declined in both rural and urban areas during the period between 1990 and 2005, this was not the case in fertility. With the largest urban-rural fertility gap in Africa, and 1.3 (in 2005) in the capital city, Addis Ababa-the lowest fertility in eastern and southern African capital cities-Ethiopia demonstrates a unique demographic transition in the region. Several demographic and socio-economic factors, including increased female age at marriage, working outside the home, and greater female high school education, are suggested as key contributors to the fertility decline in urban Ethiopia. Contraceptive use, housing shortage, and abortion are also mentioned as important factors in the fertility decline, though these factors are not examined in the models. Ethiopia has suffered from political instability, drought, and economic crisis, particularly during the periods 1998-2000 and 2002-2005. Thus one cannot rule out the effects of these factors on the fertility decline (Lindstrom and Berhanu 1999). Although the authors have addressed several important determinants of fertility, there are other factors that influence fertility which are not taken into account. Probably among the most important factors is HIV/AIDS. Severe HIV epidemics are likely to exert to downward pressure on fertility (e.g., Gregson 1994; Baschieri 2000; Mturi and Hinde 2001). As in many sub-Saharan African countries, HIV/AIDS is likely to have had some impacts on the decline of fertility in urban areas, particularly in Addis Ababa. Another potentially important factor that may contribute to the change in urban fertility but is not considered in this paper is women's autonomy, measured by the ability of women to contribute to household decisions. Given the centrality of childbearing in most sub-Saharan African societies, women's decision-making autonomy is often tied to the number of children that women bear (and, in some settings, the sex of the children). Higher levels of autonomy can enhance women's ability to control their own resources, as well as their power to make decisions about demographic outcomes such as fertility (Mason 1996; Morgan \& Niraula 1995; Obermeyer 1995). As countries like Ethiopia move into the global economy, women are attaining higher levels of decision-making autonomy in greater numbers. These changes may alter women's roles in the family and expectations about childbearing.

In Part III, both chapters 6 and 7 provide some interesting findings. In chapter 6, the authors investigate the association between women's decision-making autonomy and their nutritional status, an important topic that is ignored in many previous health-related studies. Based on data from the 2005 EDHS and using a logistic multivariate model, the authors found that the level of undernourishment varies significantly by women's decision-making autonomy, where women with low autonomy are 54 per cent more likely to be undernourished than other women. They also argue that education, employment status, and household property are pathways through which women's autonomy affects their nutritional status. However, this argument deserves further investigation. Many studies on women's health and reproductive behaviour have stated that nutritional status is regulated directly by decision-making autonomy variables, while the socio-economic variables (e.g., education, employment, and household property) affect it only indirectly by modifying the autonomy variables (e.g., Bindon and Vitzthum 2002; Hindin 2000). In chapter 7, the authors try to examine the effect of women's education, place of residence, and age at first marriage on maternal health care utilization in Ethiopia. They indicate that the health service system in Ethiopia has improved since the early 1990s, and the maternal mortality ratio has declined from 871 in 2000 to 590 deaths per 100,000 live births in 2008. While the motivation behind this study is good and sound, it is quite difficult to pin-point the theory that holds this piece together. Nowhere in the paper do the authors make reference to a conceptual framework that informs readers as to how and why they decided to include those specific variables (maternal education, place of residence, and age at marriage) in their analysis.

The chapters in Part IV deserving to be commended are 8 and 10. In chapter 8, attention is given to migration and urbanization in Ethiopia. There are relatively few studies on the topics of migration and urbanization, and these brief papers provide a new contribution. In chapter 8 , using data from three national censuses and national labor force, vital registration, and migration surveys, the authors reported a decline in rural-urban migration but a rapid increase in urban-urban migration in 1984-1999. The most important finding from chapter 10 is that migration, especially temporary migration, has helped women enter the labor force at a greater rate than men, and this was attributed to the demographic response to population-land pressure. Chapter 11 of Part V examines an interesting topic, "the process of urbanization and changing livelihoods: the case of farmers displaced in the expansion of Addis Ababa." This is a new and timely study that may have important contributions in future urban planning. It is noted that the growth of urban centers, particularly of Addis Ababa, has displaced many farmers in daily labour, with women and youth being the major victims of the effects of the livelihood crisis. The policy implication of this study is that there is a need for community participation in the planning and implementation of urban expansion programs. Chapter 12 
is another interesting and important work in Part V. In this chapter, the author critically assesses the different aspects of population vulnerability interrelationship with demographic change and response at five levels of analysis (district, sub-district, community, household, and individual). The most important aspect of this study is the choice of the approach used, which is guided by a holistic ecosystem approach. Given that the combination of factors that lead to food insecurity and malnutrition in Ethiopia is not well understood, particularly as the causality of interactions that contribute to such vulnerabilities are varied, complex, and contextually driven, an ecosystem approach is the right choice of approach and well suited to better understand the relationship between the factors contributing to population change and vulnerability. According to the author, the most demographically vulnerable households are those newly formed or old-age, female-headed, and those with many children under 10 years of age. In addition, chronic childhood malnutrition is found to be higher among vulnerable groups, especially female-headed landless households, and among those living in low-land areas with no piped water supply. Moreover, environmental degradation, land shrinkage, land and cattle pressure, and family composition are found to be related to hunger or malnutrition.

Chapters 14, 15, and 16 of Part VI focus on development policy and program evaluation. Chapter 14, titled "population, family planning, and long-term development goals," seeks to help us understand the interrelationship between population and development, a phenomenon that the author claims is timely and important for policy purposes. The major part of this chapter centres on a projection of total population to the year 2035 under two fertility decline scenarios, and links it with the growth in Gross Domestic Product (GDP). While the motivation behind the paper is good and timely, it is difficult to know the accuracy of and interpret the projected results in Table 14.1 and relate them with the results in Figure 14.3, because neither the base population nor the method used are clear. In short, more analytical clarity would have proved helpful. The next chapter is devoted to some aspects of the implementation of Ethiopia's 1993 National Population Policy (NPP) designed to address the imbalance between population growth and resources. Among other things, weak coordination and institutional arrangements, little collaboration from partners, lack of monitoring and evaluation systems, and absence of a strong legal framework have been identified as problems that have hindered the implementation of the NPP. An excellent chapter, it is not without some minor flaws. In Figure 15.1, the number of graduates shown on the vertical axis is too exaggerated, and calls for caution in interpreting them. Without going into further details, one gets the impression that the number of graduates in 1989 appears implausibly high (5), but there were only two graduates in that year. The same is true for the other calendar years. Thus, either the heading of the figure should read as "trends in intake/enrolment..." or the graph should be revised if the intention is to show the number of graduates in each year. Chapter 16 focuses on barriers to access and effective use of data and research for development policy in Ethiopia. The authors of this chapter argue that although evidence-based decision making for development policy is now well recognized in Ethiopia, there is still a paucity of dada of reliable quality and adequate coverage. It is also clearly stated that conflicting estimates of demographic and socio-economic indicators between government sources are still barriers to effective use of data for research and development policy in Ethiopia. Delays in data production are also identified as major barriers to access data. The final part (Part VII) of the book contains the conclusion and policy recommendations.

In general, regardless of the minor reservations indicated above, this book is the first in the field of demographic transition and development in Africa with particular reference to Ethiopia, describing the distinctive fertility transitions: urban areas in advanced transition, with below-replacement level in the capital city, Addis Ababa, and the rural areas in an incipient stage but still with a TFR above six children. This is a useful book that presents a number of important ideas and results. The authors' explanation of the interrelationship between the major determinants of demographic processes and development at micro and macro levels in different chapters is thoughtful and interesting. Their overall conclusions and policy implications are important for policymakers and the general public. The

book is more important and useful to policymakers not only in Ethiopia, but for other countries in the sub-Saharan African region that might have similar demographic and socio-economic development issues.

\section{References}

Baschieri, A. 2000. Relationship between HIV/AIDS Epidemic \& Demographic Processes: Tanzania Fertility. Master's Diss. University of Pisa (Italy).

Bindon, J., and V.J. Vitzthum. 2002. Household economic strategies and nutritional anthropometry of women in American Samoa and highland Bolivia. Social Science \& Medicine 54:1299-1308. 
Gregson, S. 1994. Will HIV become a major determinant of fertility in Sub-Saharan Africa? Journal of Development Studies 3(3):651-679.

Hindin, M. 2000. Women's power and anthropometric status in Zimbabwe. Social Science \& Medicine 51:1517-1528.

Lindstrom, D., and B. Berhanu. 1999. The impact of war, famine, and economic decline on marital fertility in Ethiopia. Demography 36(2):247-261.

Mason, K.O. 1996. Wives' Economic Decision-Making in the Family in Five Asian Countries. East-West Center Working Papers Population Series 86. Honolulu: East-West Center.

Morgan, N., and B. Niraula. 1995. Gender inequality and fertility in two Nepali villages. Population and Development Review 21:541-561.

Mturi, A., and A. Hinde. 2001. Fertility levels and differentials in Tanzania. Proceedings of the United Nations Workshop on Prospects for Fertility Decline in High Fertility Countries. New York, 9-11 July.

Obermeyer, C.M. 1995. Reproductive rights in the West and in the Middle East: A cross-cultural perspective, in Family, Gender, and Population in the Middle East: Policies in Context, edited by C.M. Obermeyer. Cairo: American University Press. 